\title{
A Novel Cryptic Three-Way Translocation $t(2 ; 9 ; 18)($ p23.2;p21.3;q21.33) with Deletion of Tumor Suppressor Genes in 9p21.3 and 13q14 in a T-Cell Acute Lymphoblastic Leukemia
}

\author{
Moneeb A. K. Othman, ${ }^{1}$ Martina Rincic, ${ }^{1,2}$ Joana B. Melo, ${ }^{3,4}$ Isabel M. Carreira, ${ }^{3,4}$ \\ Eyad Alhourani, ${ }^{1}$ Friederike Hunstig, ${ }^{5}$ Anita Glaser, ${ }^{1}$ and Thomas Liehr ${ }^{1}$ \\ ${ }^{1}$ Jena University Hospital, Friedrich Schiller University, Institute of Human Genetics, Kollegiengasse 10, 07743 Jena, Germany \\ ${ }^{2}$ Croatian Institute of Brain Research, Salata 12, 10000 Zagreb, Croatia \\ ${ }^{3}$ Laboratory of Cytogenetics and Genomics, Faculty of Medicine, University of Coimbra, Azinhaga Santa Comba, \\ Polo Ciências da Saúde, 3000-548 Coimbra, Portugal \\ ${ }^{4}$ Centro de Investigação em Meio Ambiente, Genética e Oncobiologia (CIMAGO), Rua Larga, 3004-504 Coimbra, Portugal \\ ${ }^{5}$ Jena University Hospital, Friedrich Schiller University, Department of Internal Medicine II (Oncology and Hematology), \\ 07749 Jena, Germany
}

Correspondence should be addressed to Thomas Liehr; thomas.liehr@med.uni-jena.de

Received 25 July 2014; Revised 18 September 2014; Accepted 20 September 2014; Published 8 October 2014

Academic Editor: Daniela Cilloni

Copyright (C) 2014 Moneeb A. K. Othman et al. This is an open access article distributed under the Creative Commons Attribution License, which permits unrestricted use, distribution, and reproduction in any medium, provided the original work is properly cited.

\begin{abstract}
Acute leukemia often presents with pure chromosomal resolution; thus, aberrations may not be detected by banding cytogenetics. Here, a case of 26-year-old male diagnosed with T-cell acute lymphoblastic leukemia (T-ALL) and a normal karyotype after standard GTG-banding was studied retrospectively in detail by molecular cytogenetic and molecular approaches. Besides fluorescence in situ hybridization (FISH), multiplex ligation-dependent probe amplification (MLPA) and high resolution arraycomparative genomic hybridization $(\mathrm{aCGH})$ were applied. Thus, cryptic chromosomal aberrations not observed before were detected: three chromosomes were involved in a cytogenetically balanced occurring translocation $\mathrm{t}(2 ; 9 ; 18)(\mathrm{p} 23.2 ; \mathrm{p} 21.3 ; \mathrm{q} 21.33)$. Besides a translocation $\mathrm{t}(10 ; 14)(\mathrm{q} 24 ; \mathrm{q} 11)$ was identified, an aberration known to be common in T-ALL. Due to the three-way translocation deletion of tumor suppressor genes CDKN2A/INK4A/p16, CDKN2B/INK4B/p15, and MTAP/ARF/p14 in 9p21.3 took place. Additionally $R B 1$ in 13q14 was deleted. This patient, considered to have a normal karyotype after low resolution banding cytogenetics, was treated according to general protocol of anticancer therapy (ALL-BFM 95).
\end{abstract}

\section{Introduction}

T-cell acute lymphoblastic leukemia (T-ALL) is a quite rare and heterogeneous disease, more common in males than in females. It accounts for $15 \%$ of childhood and $25 \%$ of adult ALL cases [1]. Underlying genetic causes of T-ALL are poorly understood and this is highlighted by the fact that T-ALL is associated with a normal karyotype in $30-50 \%$ of the cases [2, 3]. In abnormal karyotypes recurrent chromosomal aberrations are reported [4]. Regularly, promoter and enhancer elements of genes involved in T-cell development are juxtaposed with translocations in close proximity of oncogenes $[5,6]$. The most common structural chromosomal abnormalities in TALL are TCR (T-cell receptor) loci rearrangements. Breakpoints in 14q11 (TCRA/D) and 7q34 (TCR $\beta$ ) are observed frequently. Besides, deletions in the long arm of chromosome 6 may be found; the common deleted region involves mainly subband 6q16; however, candidate gene(s) have not been formally identified yet $[7,8]$. Also tumor suppressor genes have been seen to be involved in T-ALL [9].

Cryptic structural chromosomal abnormalities are still a challenge in cytogenetic standard diagnostics of acute 
leukemia. However, many cryptic aberrations have been identified by molecular cytogenetics already. Examples in T-ALL are cryptic deletions in 9p21 involving the genes CDKN2A/INK4A/p16, CDKN2B/INK4B/p15, and MTAP/ $A R F / p 14$ leading to loss of G1 checkpoint control of the cell cycle or the $R B 1$ locus in $13 \mathrm{q} 14$, which also plays a role as tumor suppressor gene in cell cycle regulation [9].

Here, a case of a young adult T-ALL patient with a novel cryptic three-way translocation, a reciprocal translocation, and submicroscopic deletions is reported.

\section{Material and Methods}

2.1. Clinical Description. A 26-year-old male presented in 1998 initially with a total white blood cell count of $20.2 \times$ $10^{9} / \mathrm{L}$, hemoglobin of $9.2 \mathrm{mmol} / \mathrm{L}$, and platelets of $126 \times$ $10^{9} / \mathrm{L}$. Bone marrow examination was consistent with T-ALL having $91 \%$ blast cells. According to flow cytometry the immunophenotype of bone marrow lymphocytes was as follows: the cells were positive for CD2 (96\%), CD8 (96\%), CD4 (92\%), CD7 (92\%), CD1A (89\%), CD10 (87\%), CyCD3 $(86 \%)$, and $\mathrm{TdT}(85 \%)$ and negative for $\alpha \mathrm{F} 1, \beta \mathrm{F} 1, \mathrm{CD} 3, \mathrm{CD} 13$, CD19, CD20, CD24, CD33, CD34, HLA-DR, MPO-7, slg, $\mathrm{TZR}-\alpha / \beta$, and $\mathrm{TZR} \gamma / \delta$. The patient was treated according to ALL-BFM 95 protocol and died eight months after initial diagnosis from serious infections and severe complications while being in complete hematological remission.

2.2. Test Done at Diagnosis. GTG-banding was done according to standard procedures. A total of 7 metaphases were available for cytogenetic evolution derived from unstimulated bone marrow of the patient and were analyzed on a banding level of 180-250 bands per haploid karyotype [11] and determined as 46,XY [7, 12]. RT-PCR performed for $T E L / A M L 1$ and $B C R / A B L$ fusion genes was reported to be negative and fluorescence in situ hybridization (FISH) analysis carried out according to manufacturer's instructions for the same loci was negative (probes used: LSI BCR/ABL and LSI TEL/AML1, Abbott Molecular/Vysis, Mannheim, Germany).

\subsection{Test Done in Retrospective}

2.3.1. Molecular Cytogenetics. FISH was done according to standard procedures and manufacturer's instructions for the following commercially available probes: LSI 13 in $13 \mathrm{q} 14.2$ (RB1, Abbott Molecular/Vysis, Mannheim, Germany), LSI IGH/BCL2 (IGH in 14q32; BCL2 in 18q21, Abbott Molecular/Vysis, Mannheim, Germany), SPEC ALK/2q11 ( $A L K$ in 2p23, Zytovision GmbH, Bremerhaven, Germany), SPEC p16/CEN9 (p16 in 9p21.3, Zytovision GmbH, Bremerhaven, Germany), SPEC BIRC3/MALT1 (BIRC3 in 11q22.2, MALT1 in 18q21.32, Zytovision, Bremerhaven, Germany), and POSEIDON MLL/MLLT3 (MLL in 11q23.3, MLLT3 in 9p21.3; Kreatech Diagnostics, Amsterdam, Netherland).

Whole chromosome painting (WCP) probe for chromosomes 2, 9, 10, 14, and 18 and bacterial artificial chromosome probes (BACs) for chromosomes 2 and 9 (Table 1) were homemade [13]. The homemade multitude multicolorbanding $(\mathrm{mMCB})$ and chromosome specific high resolution array-proven multicolor-banding (aMCB) probe sets were also applied as previously reported $[10,14,15]$.

A total of 10-15 metaphase spreads were analyzed, using a fluorescence microscope (AxioImager.Z1 mot, Zeiss) equipped with appropriate filter sets to discriminate between a maximum of five fluorochromes and the counterstain DAPI (Diaminophenylindol). Image capturing and processing were carried out using an ISIS imaging system (MetaSystems, Altlußheim, Germany).

2.3.2. DNA Isolation. Genomic DNA was extracted from cells fixed in acetic acid: methanol $(1: 3)$ by Puregene DNA Purification Kit (Gentra Systems, Minneapolis, MN, USA). DNA concentration was determined by a Nanodrop spectrophotometer. The quality of DNA was checked using agarose gel electrophoresis. DNA samples extracted from fixed cells of 2 healthy males and 2 healthy females by the same method were used as reference samples.

\subsubsection{Multiplex Ligation-Dependent Probe Amplification} (MLPA). The P377-A1 hematologic malignancies probemix and SALSA reagents were used for this study (MRC-Holland, Amsterdam, The Netherlands). Amplified probes and Genescan 500 ROX standard were separated by capillary electrophoresis using a 4-capillary ABI-PRISM 3130XL Genetic Analyzer (Applied Biosystems, Foster City, USA). Sizing of peaks and quantification of peak areas and heights were performed using GeneMarker v1.9 software (Applied Biosystems). A minimum of 4 healthy control samples were included in each run.

\subsubsection{High Resolution Array-Comparative Genomic Hybridi-} zation $(a C G H)$. aCGH was performed using Agilent SurePrint G3 Human Genome microarray 180 K (Agilent Technologies, Santa Clara, CA, USA), an oligonucleotide microarray containing approximately 180,000 probes 60 -mer with a $17 \mathrm{~kb}$ average probe spacing. Genomic DNA of patient was cohybridized with a male control DNA (Agilent Technologies, Santa Clara, CA, USA). Labeling was performed using Agilent Genomic DNA enzymatic labeling kit (Agilent) according to the manufacturers' instructions. After hybridization, the aCGH slide was scanned on an Agilent scanner and processed with Feature Extraction software (v10.7) and results were analyzed using Cytogenomics (v2.9.1.3) using ADM2 as aberration algorithm.

\section{Results of Retrospective Analysis}

As an initial test of retrospective analysis a genome wide FISH-banding applying mMCB was performed. Thereby, a previously unrecognized reciprocal and apparently balanced translocation between the three chromosomes 2, 9, and 18 was identified. Besides a known recurrent translocation of chromosomes 10 and 14 was recognized and the karyotype was suggested as 46,XY,t(2;9;18)(p23.2;p21.3;q21.33), $\mathrm{t}(10 ; 14)(\mathrm{q} 24 ; \mathrm{q} 11)$ (Figure 1). aMCB and WCP probes as 
TABle 1: (a) Probes used for characterization of the three-way translocation, their location, and obtained results. (b) Probes used for characterization of the in aCGH detected deletions, their location, and obtained results.

(a)

\begin{tabular}{|c|c|c|c|}
\hline Cytoband & Location [hg19] & Probe & Result for derivative chromosomes \\
\hline $2 \mathrm{p} 24.3$ & $\begin{array}{c}\text { chr2: } \\
16,014,784-16,140,647\end{array}$ & RP11-119F22 & Signal on der(9); no split signal \\
\hline $2 \mathrm{p} 23.3$ & $\begin{array}{c}\text { chr2: } \\
26,967,697-27,136,688\end{array}$ & RP11-106G13 & Signal on der(9); no split signal \\
\hline $2 \mathrm{p} 23.2$ & $\begin{array}{c}\text { chr2: } \\
29,415,640-29,447,593\end{array}$ & SPEC ALK & Signal on der(9); no split signal \\
\hline $9 \mathrm{p} 22.1$ & $\begin{array}{c}\text { chr9: } \\
18,717,972-18,718,524\end{array}$ & RP11-503K16 & Signal on der(18); no split signal \\
\hline $9 \mathrm{p} 22.1$ & $\begin{array}{c}\text { chr9: } \\
19,371,384-19,371,943\end{array}$ & RP11-513M16 & Signal on der(18); no split signal \\
\hline $9 \mathrm{p} 21.3$ & $\begin{array}{c}\text { chr9: } \\
20,182,493-20,361,132\end{array}$ & RP11-15P13 & Signal on der(18); no split signal \\
\hline $9 \mathrm{p} 21.3$ & $\begin{array}{c}\text { chr9: } \\
20,344,968-20,621,872\end{array}$ & MLLT3 & MLLT3-gene signal on der(18); no split signal \\
\hline $9 \mathrm{p} 21.3$ & $\begin{array}{c}\text { chr9: } \\
21,967,751-21,975,132\end{array}$ & SPEC p16 & Deletion on $\operatorname{der}(9)$ and/or der(18) \\
\hline $9 \mathrm{p} 21.3$ & $\begin{array}{c}\text { chr9: } \\
23,608,612-23,790,449\end{array}$ & RP11-946B6 & Deletion on $\operatorname{der}(9)$ and/or der(18) ish 9p21.3(RP11-946B6x0)[8] \\
\hline $9 \mathrm{p} 21.2$ & $\begin{array}{c}\text { chr9: } \\
27,937,615-27,944,495\end{array}$ & RP11-438B23 & Signal on der(9); no split signal \\
\hline $18 \mathrm{q} 21.32$ & $\begin{array}{c}\text { chr18: } \\
56,338,618-56,417,370\end{array}$ & MALT1 & MALT1-gene signal on der(18); no split signal \\
\hline $18 \mathrm{q} 21$ & $\begin{array}{c}\text { chr18: } \\
60,985,282-60,985,899\end{array}$ & BCL2 & BCL2-gene signal on der(2); no split signal \\
\hline
\end{tabular}

(b)

\begin{tabular}{|c|c|c|c|}
\hline Cytoband & Location [hg19] & Probe & Result for derivative chromosomes \\
\hline $9 \mathrm{p} 21.3$ & $\begin{array}{c}\text { chr9: } \\
21,967,751-21,975,132\end{array}$ & SPEC p16 & $\begin{array}{l}\text { ish } 9 \mathrm{p} 21.3(\mathrm{p} 16 \times 1)[4] \\
\text { nuc ish 9p21(p16x0)[64]/9p21(p16x1)[83]/ } \\
\quad 9 \mathrm{p} 21(\mathrm{p} 16 \times 2)[53]\end{array}$ \\
\hline $13 \mathrm{q} 14.2$ & $\begin{array}{c}\text { chr13: } \\
48,920,000-49,140,000\end{array}$ & LSI $13=R B 1$ & $\begin{array}{r}\text { nuc ish } 13 \mathrm{q} 14.2(R B 1 \mathrm{x} 0)[36] / \\
13 \mathrm{q} 14.2(R B 1 \mathrm{x} 1)[43] / \\
13 \mathrm{q} 14.2(R B 1 \mathrm{x} 2)[121]\end{array}$ \\
\hline
\end{tabular}

shown in Figure 2 confirmed these suggestions. Locus specific probes narrowed down the breakpoints as shown in Table 1(a). Unfortunately there was no sufficient cell pellet available to characterize the breakpoints in more detail than listed in Table 1(a). Even though closely located to the observed chromosomal breakpoints, direct involvement of the following oncogenes was excluded using locus specific FISH-probes for $A L K$ in 2p23.2, MLLT3 in 9p21.3, and MALT1 and BCL2 in 18q21.33. However, MLPA (result not shown) and aCGH (Figure 3) revealed that the $\mathrm{t}(2 ; 9 ; 18)$ is not really balanced: a deletion in $9 \mathrm{p} 21.3$ including CDKN2A/INK4A/p16, CDKN2B/INK4B/p15, and MTAP/ $A R F / p 14$ could be found as chr9: 21,252,517-21,798,676x1 and 21,817,082-23,515,821x0 (hg19) (Figure 3; Table 1(b)). Moreover, a deletion in 13q14.2 was detected as chr13: 48,982,000-49,062,000xl (hg19, Figure 3). FISH showed a mosaic condition of mixed heterozygous and homozygous deletion of 9p21.3 and 13q14.2 (Table 1(b)).

\section{Discussion}

Chromosomal translocations are considered to be the primary cause of leukemia for both acute and chronic phase. In this study, we retrospectively identified previously undetected balanced and unbalanced chromosomal and subchromosomal changes by application of molecular cytogenetics including FISH-banding, locus-specific FISH-probes, and aCGH plus MLPA. FISH-banding, especially mMCB, allows the identification of balanced and unbalanced inter- and intrachromosomal rearrangements of the whole human karyotype 


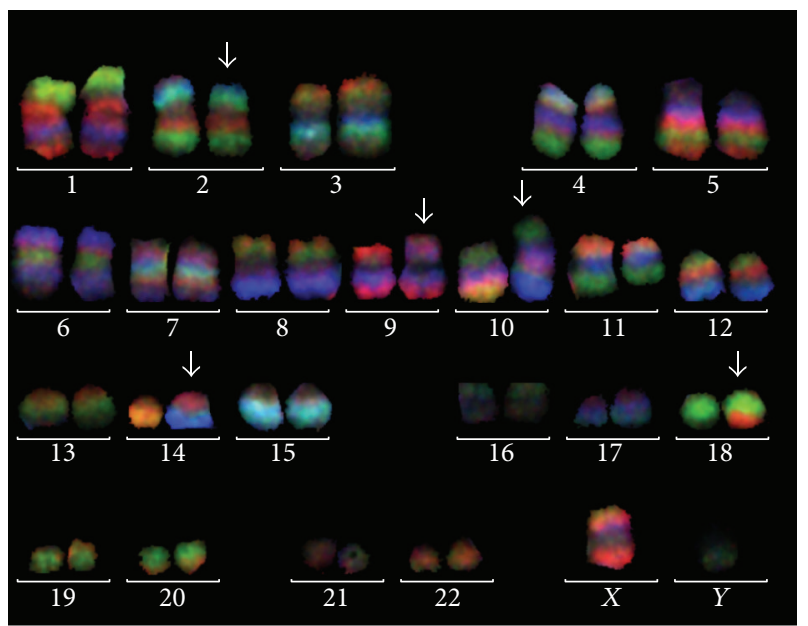

FIGURE 1: Application of mMCB showed no normal karyotype but derivative chromosomes 2, 9, 10, 14, and 18 (arrows). mMCB results are shown as overlay of three of the six used color channels. Evaluation was done as previously reported [10] using all 6 color channels and pseudocoloring. Breakpoints were determined as 2p23.2, 9p21.3, 10q24, 14q11, and 18q21.33.

in one single experiment [10]. It might be indicated to apply mMCB or comparable FISH-banding approaches routinely in T-ALL cases exhibiting poor quality of the metaphase, that is, not well spreading ones with chromosomes appearing as fuzzy with indistinct margins $[16,17]$.

In this study one well-known and one yet unreported balanced translocation event were identified for a T-ALL as $\mathrm{t}(10 ; 14)(\mathrm{q} 24 ; \mathrm{q} 11)$ and $\mathrm{t}(2 ; 9 ; 18)(\mathrm{p} 23.2 ; \mathrm{p} 21.3 ; \mathrm{q} 21.33)$, respectively. While a direct involvement of the cancer-related oncogenes $A L K$ in 2p23.2, MLLT3 in 9p21.3, and BCL2 in $18 \mathrm{q} 21.33$ could be excluded, loss of two tumor suppresser gene loci in 9p21 and in 13q14 was found.

Data from the literature confirmed that the oncogenes tested and located nearby the chromosomal breakpoints of the three-way translocation were not yet found to be involved in T-ALL: ALK located in 2p23.2 was previously detected in a variety of B- and T-cell lymphomas and nonhematopoietic solid tumors [18-23], the BCL2 gene is overexpressed in lymphomas [24,25], and the MLLT3 gene was one of the most highly upregulated transcripts and the most common fusion partner of MLL in de novo acute myeloid leukemia (AML) subtype M5 and therapy-related AML [26-28]; however, Meyer et al. [29] found that MLLT3 also plays a role in pediatric rather than adult ALL.

In the present case, an additional chromosomal translocation $\mathrm{t}(10 ; 14)(\mathrm{q} 24 ; \mathrm{q} 11)$, known as sole abnormality in $10 \%$ of T-ALL patients, was identified. Also it is present in $5 \%$ of pediatric and $30 \%$ of adult T-ALL [20,30,31]. The TLX1 gene at $10 \mathrm{q} 24$ is a transcription factor becoming overexpressed as oncogene due to its juxtaposition to a strong promoter and enhancer elements of the TCR loci at 14q11 [5, 32-34]. A favorable outcome was reported in pediatric and adult T-ALL

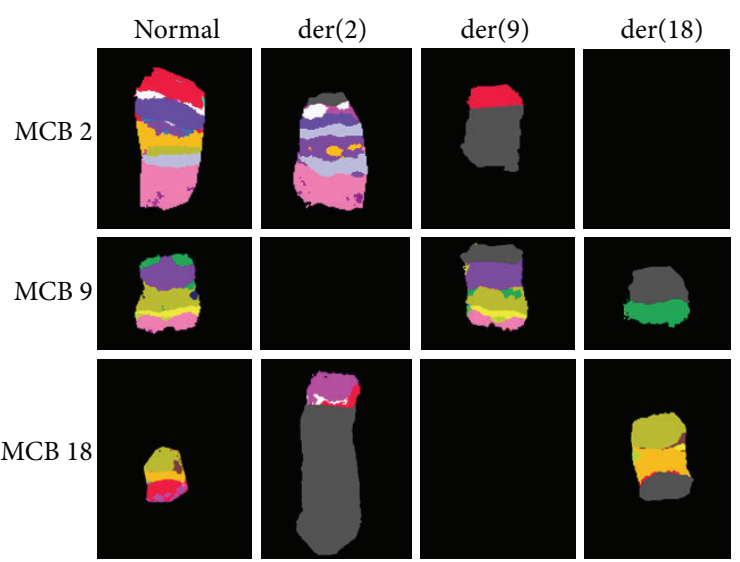

(a)
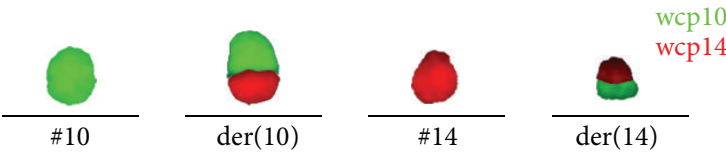

(b)

FIgURE 2: (a) Results of aMCB probe sets for chromosomes 2, 9, and 18 are shown in pseudocolor depiction, which confirmed the characterization of these three chromosomes involving rearrangement as $\mathrm{t}(2 ; 9 ; 18)(\mathrm{p} 23.2 ; \mathrm{p} 21.3 ; \mathrm{q} 21.33)$. (b) Whole chromosome paints (wcp) for chromosomes 10 and 14 confirmed that the $\mathrm{t}(10 ; 14)(\mathrm{q} 24 ; \mathrm{q} 11)$ was independent of the $t(2 ; 9 ; 18)$.

to be associated with the $\mathrm{t}(10 ; 14)$ or TLX1 gene overexpression $[5,20,35]$.

Even though balanced rearrangements are known to be typical for hematopoietic malignancies to date, only a limited number of studies have used whole genome directed FISH approaches to identify cryptic chromosomal abnormalities in ALL patients [36-38]. Still, in ALL it is uncommon to see three-way translocations. However, due to low metaphase resolution in ALL the real incidence of three-way translocations is currently unknown.

The present report highlights that after identification of apparently balanced chromosomal aberrations, it is still necessary to screen for further unbalanced submicroscopic abnormalities by molecular approaches such as MLPA and aCGH. However, also a confirmation of the results by molecular cytogenetics is necessary, as aCGH was partially misclassified a mix of homo- and heterozygote deletions as pure homozygote ones.

9p21.3 deletions, which lead to the loss of CDKN2A/ INK4A/p16, CDKN2B/INK4B/p15, and MTAP/ARF/p14 tumor suppressor genes expression, are the most predominant aberrations seen in precursor B-cell ALL $(\sim 20 \%$ of the cases) and T-ALL ( $>60 \%$ of the case) [39-42]. Besides also a deletion of $R B 1$ gene resulting in inactivation of another tumor suppressor gene expression was identified. $R B 1$ is rarely reported to be deleted in T-ALL. In contrast, deletion of $R B 1$ has been detected in 30\% of B-ALL and nearly to $60 \%$ in B-CLL cases $[43,44]$. Thus, $R B 1$ pathway was identified as potential targets for therapy of ALL $[45,46]$. 

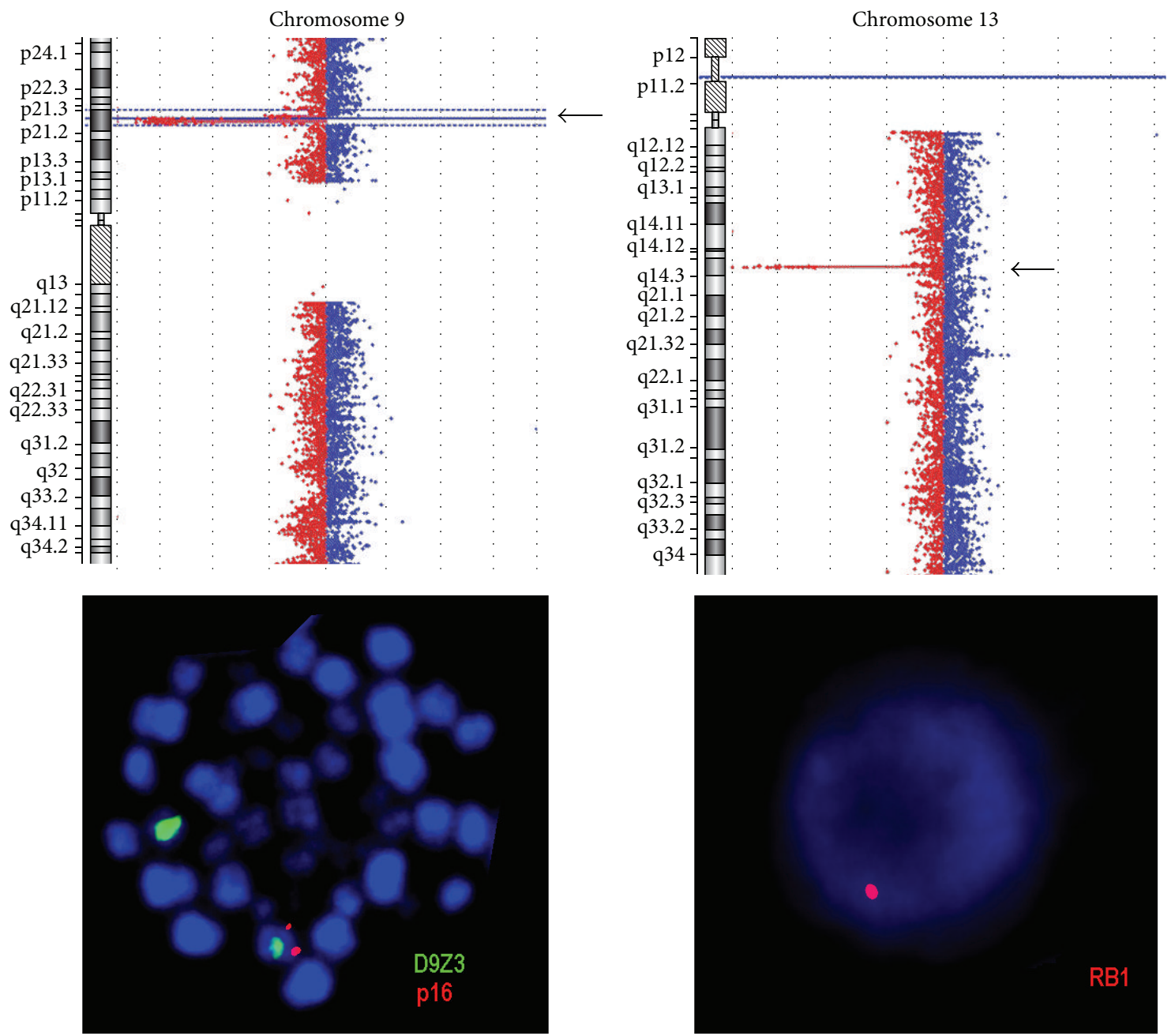

FIGURE 3: aCGH confirmed deletions in 9p21.3 and 13q14.2 (arrows) detected initially by MLPA (result not shown). FISH confirmed presence of these deletions in metaphase and/or interphase. Examples for heterozygote deletions of 9p21.3 and 13q14.2 are depicted; probes specific for the corresponding tumor suppressor genes were labeled in red; centromeric probe for chromosome 9 (D9Z3) was labeled in green.

\section{Conclusion}

In conclusion, we report a case of T-ALL with complex chromosomal aberrations. Even if at time of diagnosis the deletion on 9p21.3 would have been detected and accordingly treated, it remains unclear what influence the other tumor suppressors and oncogenes (possibly) activated by the complex rearrangements would have had for the clinical outcome. Overall, the present case stresses the necessity to study hematological malignancies by different means to get a comprehensive picture of the genetic changes in connection with the acquired disease, as aCGH or MLPA alone would only have identified the imbalanced rearrangements, while molecular cytogenetics predominantly gave hints on the presence of balanced rearrangements.

\section{Conflict of Interests}

The authors declare that there is no conflict of interests regarding the publication of this paper.

\section{Acknowledgments}

This research paper is supported in part by the DAAD and KAAD.

\section{References}

[1] C.-H. Pui, M. V. Relling, and J. R. Downing, "Mechanisms of disease: acute lymphoblastic leukemia," The New England Journal of Medicine, vol. 350, no. 15, pp. 1535-1548, 2004.

[2] C. J. Harrison, "Key pathways as therapeutic targets," Blood, vol. 118, no. 11, pp. 2935-2936, 2011.

[3] A. Vitale, A. Guarini, C. Ariola et al., "Adult T-cell acute lymphoblastic leukemia: Biologic profile at presentation and correlation with response to induction treatment in patients enrolled in the GIMEMA LAL 0496 protocol," Blood, vol. 107, no. 72, pp. 473-479, 2006.

[4] C. Graux, J. Cools, L. Michaux, P. Vandenberghe, and A. Hagemeijer, "Cytogenetics and molecular genetics of T-cell acute lymphoblastic leukemia: from thymocyte to lymphoblast," Leukemia, vol. 20, no. 9, pp. 1496-1510, 2006. 
[5] A. A. Ferrando, D. S. Neuberg, R. K. Dodge et al., "Prognostic importance of TLX1 (HOX11) oncogene expression in adults with T-cell acute lymphoblastic leukaemia," The Lancet, vol. 363, no. 9408, pp. 535-536, 2004.

[6] S. H. Oram, J. Thoms, J. I. Sive et al., "Bivalent promoter marks and a latent enhancer may prime the leukaemia oncogene LMO1 for ectopic expression in T-cell leukaemia," Leukemia, vol. 27, no. 6, pp. 1348-1357, 2013.

[7] P. B. Sinclair, A. Sorour, M. Martineau et al., "A fluorescence in situ hybridization map of $6 \mathrm{q}$ deletions in acute lymphocytic leukemia: Identification and analysis of a candidate tumor suppressor gene," Cancer Research, vol. 64, no. 12, pp. 40894098, 2004.

[8] B. Cauwelier, N. Dastugue, J. Cools et al., "Molecular cytogenetic study of 126 unselected T-ALL cases reveals high incidence of TCR $\beta$ locus rearrangements and putative new T-cell oncogenes," Leukemia, vol. 20, no. 7, pp. 1238-1244, 2006.

[9] P. van Vlierberghe and A. Ferrando, "The molecular basis of T cell acute lymphoblastic leukemia," Journal of Clinical Investigation, vol. 122, no. 10, pp. 3398-3406, 2012.

[10] A. Weise, A. Heller, H. Starke et al., "Multitude multicolor chromosome banding (mMCB) - a comprehensive one-step multicolor FISH banding method," Cytogenetic and Genome Research, vol. 103, no. 1-2, pp. 34-39, 2003.

[11] U. Claussen, S. Michel, P. Mühlig et al., "Demystifying chromosome preparation and the implications for the concept of chromosome condensation during mitosis," Cytogenetic and Genome Research, vol. 98, no. 2-3, pp. 136-146, 2002.

[12] F. Mitelman, Ed., ISCN 1995: An International System for Human Cytogenetic Nomenclature (1995), S Karger, Basel, Switzerland, 1995.

[13] A. Weise, H. Starke, A. Heller et al., "Chromosome 2 aberrations in clinical cases characterised by high resolution multicolour banding and region specific FISH probes," Journal of Medical Genetics, vol. 39, no. 6, pp. 434-439, 2002.

[14] A. Weise, K. Mrasek, I. Fickelscher et al., "Molecular definition of high-resolution multicolor banding probes: first within the human DNA sequence anchored FISH banding probe set," Journal of Histochemistry and Cytochemistry, vol. 56, no. 5, pp. 487-493, 2008.

[15] T. Liehr, A. Heller, H. Starke et al., "Microdissection based high resolution multicolor banding for all 24 human chromosomes," International Journal of Molecular Medicine, vol. 9, no. 4, pp. 335-339, 2002.

[16] H. Mkrtchyan, M. Glaser, M. Gross et al., "Multicolor-FISH applied to resolve complex chromosomal changes in a case of T-ALL (FAB L2)," Cytogenetic and Genome Research, vol. 114, no. 3-4, pp. 270-273, 2006.

[17] W. Al Achkar, A. Wafa, H. Mkrtchyan, F. Moassass, and T. Liehr, "A unique complex translocation involving six different chromosomes in a case of childhood acute lymphoblastic leukemiawith the Philadelphia chromosome and adverse prognosis," Oncology Letters, vol. 1, no. 5, pp. 801-804, 2010.

[18] A. Barreca, E. Lasorsa, L. Riera et al., "Anaplastic lymphoma kinase in human cancer," Journal of Molecular Endocrinology, vol. 47, no. 1, pp. R11-R23, 2011.

[19] R. Chiarle, C. Voena, C. Ambrogio, R. Piva, and G. Inghirami, "The anaplastic lymphoma kinase in the pathogenesis of cancer," Nature Reviews Cancer, vol. 8, no. 1, pp. 11-23, 2008.

[20] S. Chiaretti and R. Foà, "T-cell acute lymphoblastic leukemia," Haematologica, vol. 94, no. 2, pp. 160-162, 2009.
[21] R. R. Einerson, P. J. Kurtin, G. A. Dayharsh, T. K. Kimlinger, and E. D. Remstein, "FISH is superior to PCR in detecting $\mathrm{t}(14 ; 18)(\mathrm{q} 32 ; \mathrm{q} 21)-\mathrm{IgH} / \mathrm{bcl}-2$ in follicular lymphoma using paraffin-embedded tissue samples," The American Journal of Clinical Pathology, vol. 124, no. 3, pp. 421-429, 2005.

[22] M. Soda, Y. L. Choi, M. Enomoto et al., "Identification of the transforming EML4-ALK fusion gene in non-small-cell lung cancer," Nature, vol. 448, no. 7153, pp. 561-566, 2007.

[23] W. Wan, M. S. Albom, L. Lu et al., "Anaplastic lymphoma kinase activity is essential for the proliferation and survival of anaplastic large-cell lymphoma cells," Blood, vol. 107, no. 4, pp. 1617-1623, 2006.

[24] J. Iqbal, V. T. Neppalli, G. Wright et al., "BCL2 expression is a prognostic marker for the activated B-cell-like type of diffuse large B-cell lymphoma," Journal of Clinical Oncology, vol. 24, no. 6, pp. 961-968, 2006.

[25] L. Impera, F. Albano, C. Lo Cunsolo et al., "A novel fusion $5^{\prime}$ AFF3/3'BCL2 originated from a $t(2 ; 18)(\mathrm{q} 11.2 ; \mathrm{q} 21.33)$ translocation in follicular lymphoma," Oncogene, vol. 27 , no. 47 , pp. 6187-6190, 2008.

[26] L. Tsao, H. Y. Draoua, I. Osunkwo et al., "Mature B-cell acute lymphoblastic leukemia with $\mathrm{t}(91 ; 11)$ translocation: a distinct subset of B-cell acute lymphloblastic leukemia," Modern Pathology, vol. 17, no. 7, pp. 832-839, 2004.

[27] N. Blin, F. Méchinaud, P. Talmant et al., "Mature B-cell lymphoblastic leukemia with MLL rearrangement: an uncommon and distinct subset of childhood acute leukemia," Leukemia, vol. 22, no. 5, pp. 1056-1059, 2008.

[28] M. de Braekeleer, F. Morel, M.-J. le Bris, A. Herry, and N. DouetGuilbert, "The MLL gene and translocations involving chromosomal band 11q23 in acute leukemia," Anticancer Research, vol. 25, no. 3, pp. 1931-1944, 2005.

[29] C. Meyer, B. Schneider, S. Jakob et al., "The MLL recombinome of acute leukemias," Leukemia, vol. 20, no. 5, pp. 777-784, 2006.

[30] I. Riz, T. S. Hawley, T. V. Luu, N. H. Lee, and R. G. Hawley, "TLX1 and NOTCH coregulate transcription in T cell acute lymphoblastic leukemia cells," Molecular Cancer, vol. 9, article 181, 2010.

[31] M. D. Kraszewska, M. Dawidowska, T. Szczepański, and M. Witt, "T-cell acute lymphoblastic leukaemia: recent molecular biology findings," British Journal of Haematology, vol. 156, no. 3, pp. 303-315, 2012.

[32] I. D. Dubé, S. C. Raimondi, D. Pi, and D. K. Kalousek, "A new translocation, $\mathrm{t}(10 ; 14)(\mathrm{q} 24 ; \mathrm{q} 11)$, in T cell neoplasia," Blood, vol. 67, no. 4, pp. 1181-1184, 1986.

[33] K. de Keersmaecker and A. A. Ferrando, "TLX1-induced T-cell acute lymphoblastic leukemia," Clinical Cancer Research, vol. 17, no. 20, pp. 6381-6386, 2011.

[34] S. Padhi, R. Sarangi, P. Mohanty et al., "Cytogenetic profile of pediatric acute lymphoblastic leukemia (ALL): analysis of 31 cases with review of literature," Caryologia, vol. 64, no. 1, pp. 33-41, 2011.

[35] S. C. Raimondi, “T-lineage acute lymphoblastic leukemia (TALL)," Atlas of Genetics and Cytogenetics in Oncology and Haematology, no. 4, 2007.

[36] J. D. Rowley, S. Reshmi, K. Carlson, and D. Roulston, "Spectral karyotype analysis of T-cell acute leukemia," Blood, vol. 93, no. 6, pp. 2038-2042, 1999.

[37] B. Poppe, B. Cauwelier, H. van Limbergen et al., "Novel cryptic chromosomal rearrangements in childhood acute lymphoblastic leukemia detected by multiple color fluorescent in situ hybridization," Haematologica, vol. 90, no. 9, pp. 1179-1185, 2005. 
[38] C. Karst, M. Gross, D. Haase et al., "Novel cryptic chromosomal rearrangements detected in acute lymphoblastic leukemia detected by application of new multicolor fluorescent in situ hybridization approaches," International Journal of Oncology, vol. 28, no. 4, pp. 891-897, 2006.

[39] D. Mirebeau, C. Acquaviva, S. Suciu et al., "The prognostic significance of CDKN2A, CDKN2B and MTAP inactivation in B-lineage acute lymphoblastic leukemia of childhood. Results of the EORTC studies 58881 and 58951," Haematologica, vol. 91, no. 7, pp. 881-885, 2006.

[40] C. G. Mullighan, S. Goorha, I. Radtke et al., "Genome-wide analysis of genetic alterations in acute lymphoblastic leukaemia," Nature, vol. 446, no. 7137, pp. 758-764, 2007.

[41] M. Kim, S.-H. Yim, N.-S. Cho et al., "Homozygous deletion of CDKN2A (p16, p14) and CDKN2B (p15) genes is a poor prognostic factor in adult but not in childhood B-lineage acute lymphoblastic leukemia: a comparative deletion and hypermethylation study," Cancer Genetics and Cytogenetics, vol. 195, no. 1, pp. 59-65, 2009.

[42] T. Szczepański, C. J. Harrison, and J. J. van Dongen, "Genetic aberrations in paediatric acute leukaemias and implications for management of patients," The Lancet Oncology, vol. 11, no. 9, pp. 880-889, 2010.

[43] H. Cavé, H. Avet-Loiseau, I. Devaux et al., "Deletion of chromosomal region 13q14.3 in childhood acute lymphoblastic leukemia," Leukemia, vol. 15, no. 3, pp. 371-376, 2001.

[44] C. J. Schwab, L. Chilton, H. Morrison et al., "Genes commonly deleted in childhood B-cell precursor acute lymphoblastic leukemia: association with cytogenetics and clinical features," Haematologica, vol. 98, no. 7, pp. 1081-1088, 2013.

[45] C. J. Harrison and L. Foroni, "Cytogenetics and molecular genetics of acute lymphoblastic leukemia," Reviews in Clinical and Experimental Hematology, vol. 6, no. 2, pp. 91-113, 2002.

[46] K. de Keersmaecker, P. Marynen, and J. Cools, "Genetic insights in the pathogenesis of T-cell acute lymphoblastic leukemia," Haematologica, vol. 90, no. 8, pp. 1116-1127, 2005. 


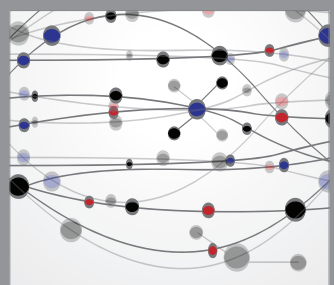

The Scientific World Journal
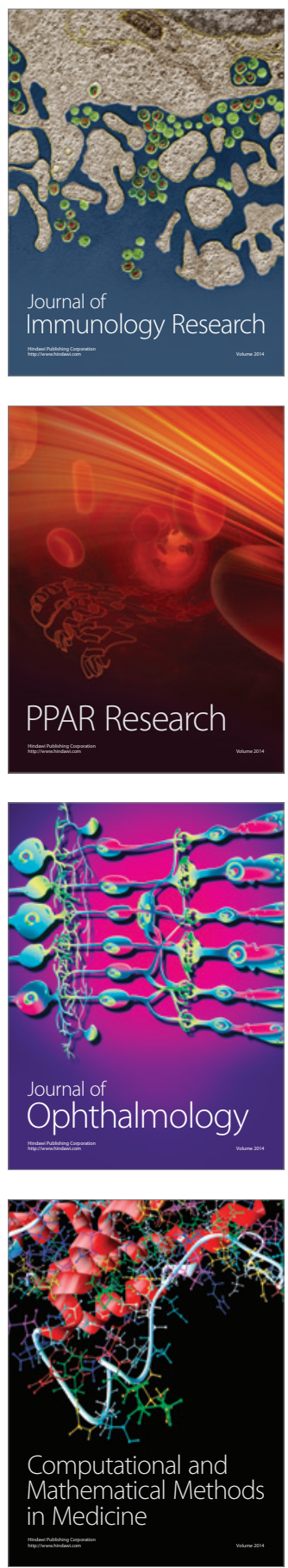

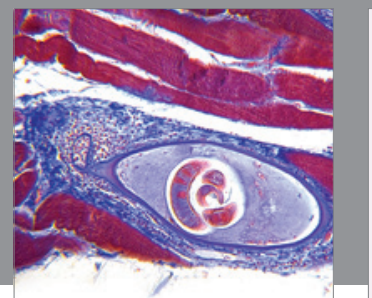

Gastroenterology

Research and Practice
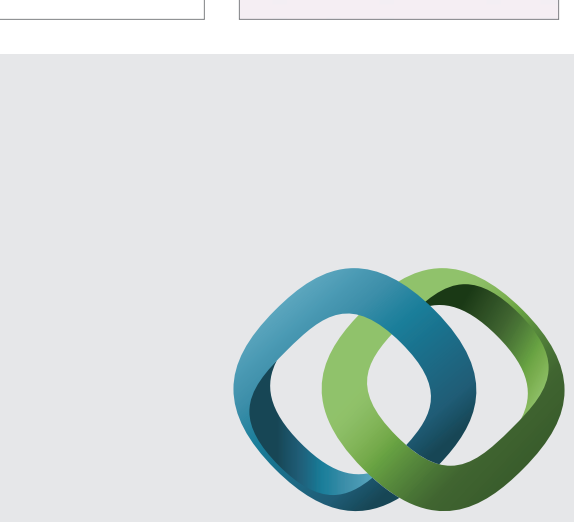

\section{Hindawi}

Submit your manuscripts at

http://www.hindawi.com
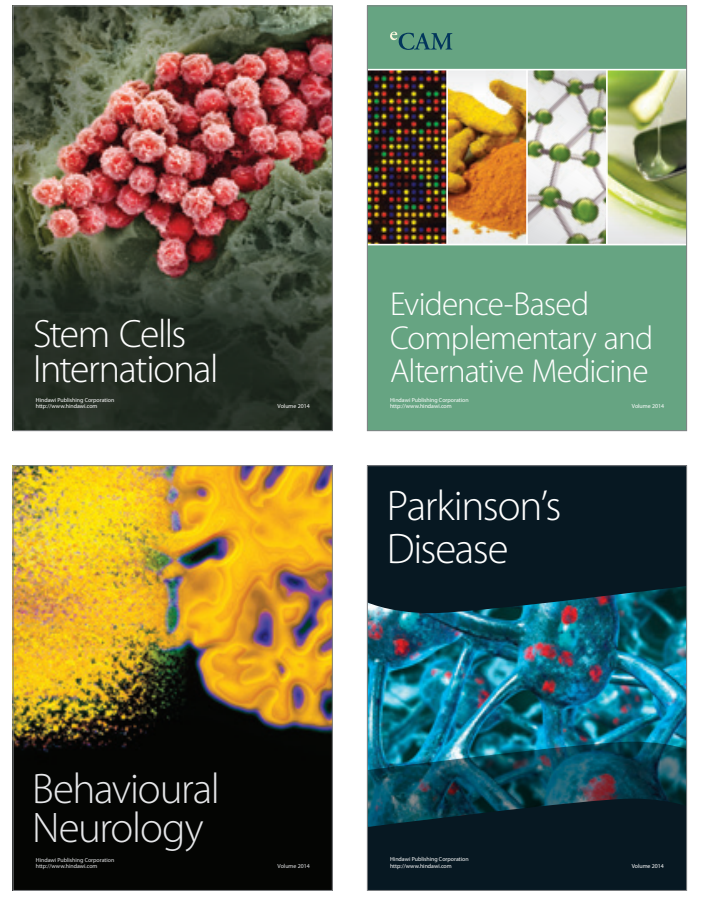
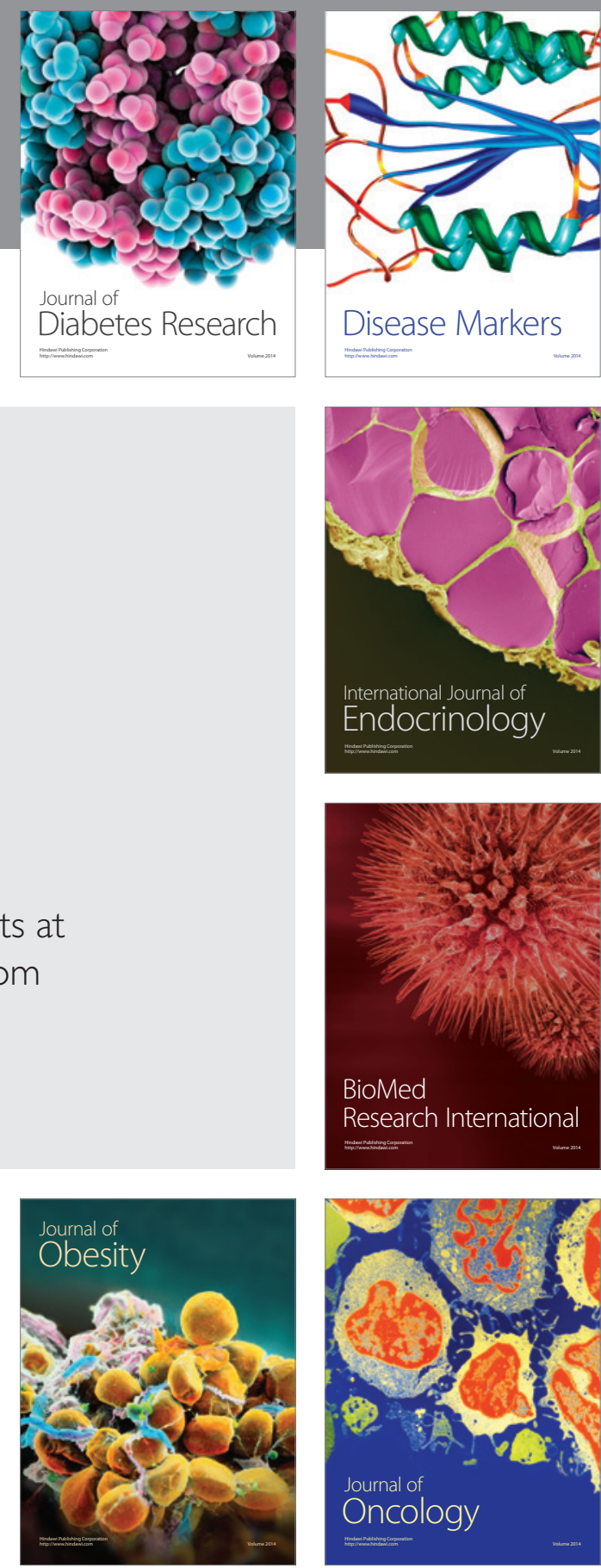

Disease Markers
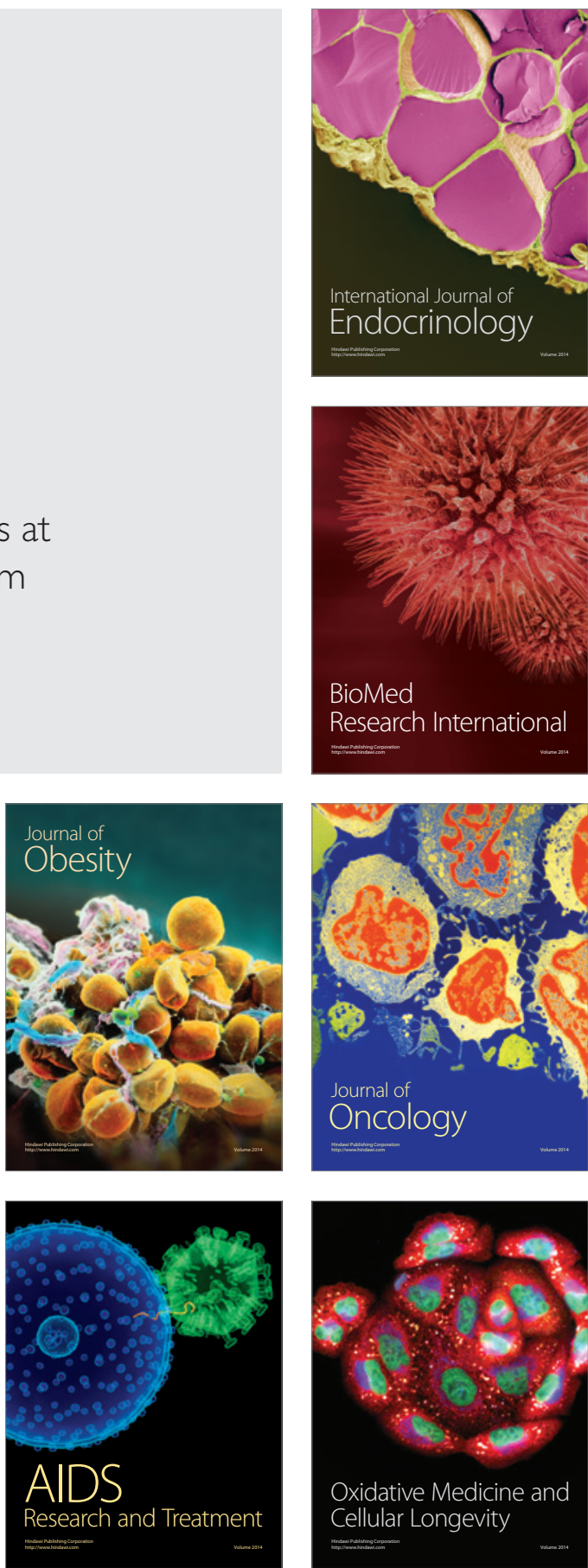